\title{
Well Placement Optimization Using Firefly Algorithm AND Crow Search Algorithm
}

\author{
Jahedul ISLAM $M^{1}$, Pandian VASANT ${ }^{2}$, Berihun Mamo NEGASH ${ }^{3}$, \\ Atulan GUPTA ${ }^{4}$, Junzo WATADA ${ }^{5}$, Anirban BANIK ${ }^{6}$ \\ ${ }^{1}$ Department of Fundamental and Applied Sciences, University of Technology Petronas, Malaysia \\ ${ }^{2}$ University of Technology Petronas, Malaysia \\ ${ }^{3}$ Shale Gas Research Group, Institute of Hydrocarbon Recovery, and Petroleum Engineering \\ Department, University of Technology Petronas, Malaysia \\ ${ }^{4}$ Department of Electrical \& Electronic Engineering, Chittagong University of Engineering and \\ Technology, Chittagong, Bangladesh \\ ${ }^{5}$ Invited Researcher, IPS Research Center, Waseda University, Japan \\ ${ }^{6}$ National Institute of Technology Agartala, Agartala, India \\ *Corresponding Author: Pandian VASCANT (Email: pvasant@gmail.com) \\ (Received: 4-Apr-2020; accepted: 18-Jul-2020; published: 30-Sep-2020) \\ DOI: http://dx.doi.org/10.25073/jaec.202043.287
}

\begin{abstract}
Optimization of well placement is one of the main difficult factors in the development process in the oil and gas industry. The well placement optimization is high dimensional, multi-modal and discontinuous. In previous research, conventional and non-conventional optimization techniques have been applied to resolve this problem. However, gradient-free optimization techniques such as genetic algorithm and particle swarm optimization which is considered as the most efficient algorithms in this area suffer from local optima. In this article, two new metaheuristic optimization techniques, namely, crow search algorithm and firefly algorithm are applied to the well placement optimization problem and their applications to maximize the net profit value are studied. To study the performance of the firefly and crow search algorithm, Eclipse and MATLAB environment are used. The proposed techniques are compared to popular established methods for optimizing well placement. Results show that the firefly algorithm is proved to be efficient and effective compared to other established techniques. However, the standard crow search algorithm is not suited to this problem.
\end{abstract}

\section{Keywords}

Reservoir simulation, metaheuristic, well placement optimization, nonlinear optimization problem, multimodal optimization; firefly algorithm; crow search algorithm.

\section{Introduction}

Well placement optimization has been a major issue in the field development process for a while due to its high dimensional, discontinuous and multimodal objective function. For the successful supply and longevity of the operation, placement selection of such well is very important. In recent years, to deal with the increasing global energy demand the correct well placement optimization has been at the center of many studies [1]-[6]. There are several processes of finding out the best possible place for well to ensure uninterrupted oil supply. Still, due to the vast infrastructural work related to such place- 
ment, it is very crucial to make sure that the well is going to be in the best available area. In brief, net profit value should be kept under consideration while running the well placement process. In order to maximize net profit value, several works have already been done with different mathematical algorithms. Previous studies have established that algorithms based on gradient and derivatives remain quiet inconsistent and ineffective due to the non-smooth, discontinuous and high dimensional objective function $[1,7]$. Some prior research was able to find local optima using gradient-based algorithms [8]. Again, some other well-known techniques such as mixed-integer programming [9], multivariate interpolation algorithms [10], etc. were also used to find the possible best location. However, these methods failed to live up to the expectation and hence researchers put more emphasis on non-classical methods. These methods are inspired by different natural phenomenon and showed more viability in finding global optimum value.

At first, Guyaguler and Horne used GA to optimize well location and injection rate by considering the net present value (NPV) as the objective function [11]. Quality maps are incorporated as nonlinear constraints which helped to determine the correct location for the correct placement of the well [12]. Lyons and Nasrabadi reduced the calculation time by four times by combining pseudo-history matching with genetic algorithms (GA) [13]. Chang, Y. in his research work, showed that NSGA II is an effective and powerful method for solving multiobjective problems [14]. In another study, it is observed that the genetic algorithm is effective and robust for accurately solving the well placement problem [15]. Overall, GA is one of the most popular technique for optimization purposes in well location optimization problems. Generally speaking, GA can find the global optimal value, but the convergence speed is slow. The genetic algorithm-based optimization method was used effectively, but doubt was cast upon issues like absolute convergence and stability [16]. Again, such algorithms have limitations like non-linearity and dis-continuity $[17,18]$. Onwunalu used PSO in his research, and has reduced the search space by gradually moving from an exploration mode to an exploitation mode [19]. But this gradual change may affect the result of different search space. Feng et al. implemented the PSO algorithm proposed by Clerc, which reduced the search process $[20,21]$. In the PSO algorithm, the neighborhood topology allows different modes of flight between its particles which provides different searches for swarms in the landscape. The researchers solved the problem of optimizing the well location by utilizing random neighborhood topology with PSO [7, 22]. This solution provides better results and avoids local optimization. But more recent researches are mainly focused on hybrid combinations. In [23], a hybrid of approximation algorithms and linear relaxation with the classical heuristic algorithm was developed in order to gain better results in a more precise time. Moreover, authors in [24], used local search techniques. Another combination named "Baldwin effect" was deployed in [25, 26]. Authors in [27], used hybrid particle swarm differential evolution (HPSDE) to find the optimum solution for well placement problems. From the result, it is clear that HPSDE algorithm outperforms both DE and PSO algorithms. Dossary and Nasrabadi [28] stated that the three main parameters of imperialist competition algorithm (ICA) are specific to the test field. Siddiqui et al. [29] compared the performance of DE with PSO and CMA-ES. However, they have found that the DE presented better performance than the PSO and CMA-ES, but greater variance is observed. Algorithms such as genetic algorithm (GA), particle swarm optimization (PSO), differential evolution (DE), and covariance matrix adaptation evolution strategy (CMA-ES) are becoming more and more popular day by day. Yet their efficiency and effectiveness are still not promising since the methods have many limitations. The main challenge faced by many researchers is to tackle highly multimodal optimization problem. For multimodal optimization applications, the study of Yang indicated that firefly algorithm is superior to existing metaheuristic algorithm [30]. Another study found that FA can manage highly non-linear multimodal optimization problems in a natural and efficient way since local attraction are more prominent than long-distance attraction [31]. From [32], it is clear that the Fire- 
fly algorithm offers better performance than the optimization of particle swarms in solving noisy nonlinear problems. Hence, it is expected that well placement optimization can be tackled more efficiently by FA. Another challenge in this field is an expensive objective function which creates a major problem for metaheuristic algorithms as metaheuristic algorithms require many parameters to be tuned by running the algorithm many times. To alleviate the problem, crow search algorithm can be considered as it requires fewer parameters to adjust and is easier to implement (2 parameters). For the above reasons, the authors are motivated to apply FA and CSA to solve these problems. To the best of our knowledge, there have been no researches on the application of CSO and FA to deal with well placement optimization problem. Hence the novelty of this study includes the implementation of FA and CSO on well placement optimization. To provide enhancement in the results and to extract maximum NPV from input data an advanced algorithm has been employed in this research. Furthermore, a comparative study with other methods from the literature review will also be provided to validate the result. In past, most research work has reported the convergence curve to show the performance of the algorithm. However, the end result of the algorithm does not show the efficiency and effectiveness of the algorithm. Hence, in this study, to evaluate the performance of the proposed algorithms several criteria are considered.

The overall paper presentation can be categorized in the following manner: The first sections represents an overview and recent works on well placement optimization. Section 2 depicts problem formulation. The methodology of this study is presented in section 3. Section 4 represents the result analysis. Sections 5 concludes this study.

\section{Well placement optimization problem formulation}

The well placement optimization, in general, can be formulated as:

$$
\begin{array}{r}
\operatorname{Max} R\left(u^{n}\right) \\
R\left(u^{n}\right)=N P V\left(u^{n}\right)
\end{array}
$$

Subjected to:

$$
L B \leq u^{n} \leq U B, \forall n \in(0,1,2,3, \ldots, N-1),
$$

here $u^{n}$ represents well coordinates, NPV presents net profit value, LB and UB are lower bound and upper bound of the reservoir respectively.

The prime motivation behind well placement optimization is to make sure that the expenditure remains minimum while maximizing the net profit. NPV changes randomly with the change of co-ordinates value hence well placement. The variables used in (4) are shown in Tab. 1 depicted from [6]. Eclipse simulation was used to calculate cumulative oil production, cumulative water production's value.

$$
\begin{aligned}
N V P & =\sum_{i=1}^{T} \frac{Q_{0} P_{0}+Q_{g} P_{g}-Q_{w} C_{w}-O P E X}{(1+D)^{i}} \\
& -C A P E X
\end{aligned}
$$

\section{Methodology}

Metaheuristic algorithms are stochastic algorithms and non-deterministic in nature. It was first developed in 1995 by Kennedy and Eberhart [33]. There are various types of metaheuristic methods like local search, simulated annealing, Tabu search, variable neighborhood search, Population-based or trajectorybased search, etc. And among the populationbased search process, some of the most popular algorithms are - Genetic algorithm, Particle swarm optimization, etc. Metaheuristic provides more efficiency than heuristic algorithms. 
Tab. 1: Variable used for NPV formulation.

\begin{tabular}{|l|l|}
\hline$Q_{0}$ is cumulative oil production & OPEX is the operational expenditure \\
\hline$Q_{w}$ is cumulative water production & OPEX is the operational expenditure \\
\hline$P_{0}$ is oil price & D is the discount rate \\
\hline $\begin{array}{l}C_{w} \text { is cost per unit volume } \\
\text { of produced water }\end{array}$ & $\begin{array}{l}\text { T is the number of years passed } \\
\text { since the production has started }\end{array}$ \\
\hline$P_{g}$ gas price & $Q_{g}$ cumulative gas production \\
\hline
\end{tabular}

\subsection{Firefly algorithm}

Firefly algorithm (FA) is one of the most popular swarm intelligence-based algorithms. The algorithm was first developed by Yang in 2008 as a solution for optimization related problems. Firefly algorithm mainly inspired by the way firefly beetle attract their mate. According to the algorithm, brighter fireflies attract the less bright fireflies. Similarly, the current best solutions lead the previous best solution towards the optimum output. Figure 1 shows the flow diagram of firefly algorithm. The brightness, $\beta$, and step length of each random movement, $\alpha^{t+1}$, can be found as

$$
\begin{aligned}
& \beta=\beta_{0} e^{-\gamma r^{2}} \\
& \alpha^{t+1}=\alpha^{t} \alpha_{0} .
\end{aligned}
$$

At the beginning of the algorithm a random feasible solution is generated and after each iteration, it compares the present calculated solution with the previous one. Finally, the brightest of the acquired solutions will take the lead. for example, firefly $i$ with less brightness will be attracted to a brighter firefly $j$ according to (7) given as below-

$$
X_{i}^{t+1}=X_{i}^{t}+\beta\left(X_{j}^{t}-X_{i}^{t}\right)+\alpha \varepsilon_{i}^{t},
$$

where

$\beta_{0}$ : brightness of $X_{i}$ at $r=0$,

$\gamma:$ An algorithm parameter which indicates how much a distant firefly is related with its nearest firefly.

$\alpha$ : step length of each random movement.

$\varepsilon$ : a random vector from uniform distribution between 0 and 1 .

\subsection{Crow search algorithm}

Crow search algorithm (CSA) is a populationbased metaheuristic algorithm for solving optimizing solution of a practical problem. This algorithm was first developed by Askarzadeh [34]. Crow is one of the most cunning birds and possesses remarkable intelligence. They can recall faces or, objects, can communicate with other group members via some complex skills and hide and retrieve hidden food. The classical crow search algorithm was built based on the concept of how a crow hides its food and retrieve it later. Figure 2 represents the flow diagram of the crow search algorithm.

At first, crow selects a random place to hide their food. Secondly, crow analyses the quality of the selected place. Thirdly, crow starts finding out the place of food hidden by another crow. Finally, they monitor their caches to prohibit from being sneaked. In this way, they can remember their hidden food place for several weeks and find that food when necessary. Using their sharp memory crow also finds out the hidden food of another crow as well. If in an environment with $d$ dimension and $N$ number crows are present, then the position of crows $i$ at iteration iter is given by:

$$
X^{i, i t r}=\left[X_{1}^{i, i t r}, X_{2}^{i, i t r}, \ldots \ldots \ldots, X_{d}^{i, i t r}\right]
$$

where $i=1,2, \ldots, \& i t r=1,2, \ldots$

Every crow flies around and searches for a better hiding place. Such individual searches can be termed as local search. And among the searches by a certain crow, the best possible place is selected. The same thing is applicable when a crow tries to find the hidden food of another crow. It starts following the target crow and monitors every position where that target crow flies to. And 


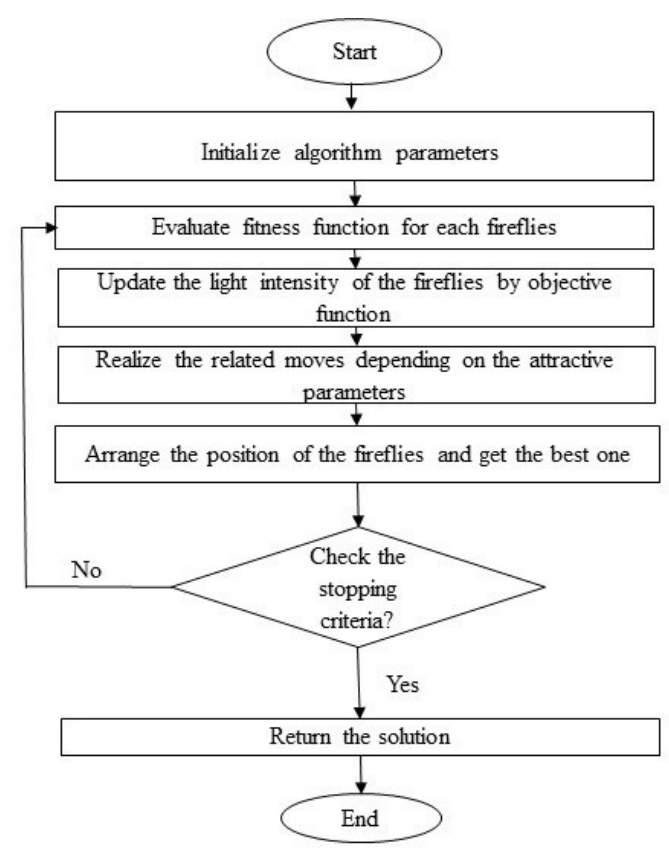

Fig. 1: Flow chart of Firefly algorithm.

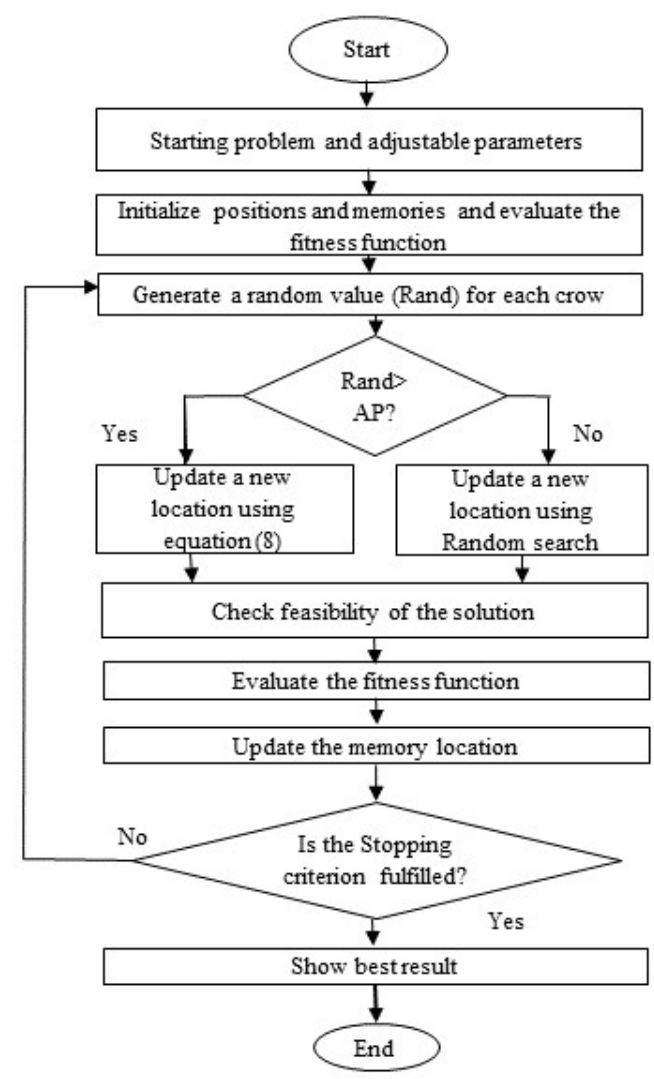

Fig. 2: Flow chart of CSA. out of those places, the crow finds out the hidden food and steal it.

In [18] Askarzadeh explained such a scenario with a beautiful example. Suppose crow $j$ wishes to visit its cache $M^{j, i t r}$ at iter iteration. At the same time crow $i$ starts following that crow to steal $j$ 's food. At this point, there may appear two possible solutions:

Case 1: When crow does not notice that it is being followed by crow $i$, crow $j$ will lead crow $i$ towards his hiding place. Position of crow $i$ will be changed as follows :

$$
\begin{aligned}
& X^{i, i t r+1}=X^{i, i t r} \\
& +r_{i} * f_{l}^{i, i t r} *\left(M^{j, i t r}-X^{i, i t r}\right), r_{i} \geq A P_{i}^{i t r},
\end{aligned}
$$

where $r$ is a random number between 0 and 1 and $f_{l}^{i, i t r}$ denotes the flight length of crow $i$ at iter iteration.

Case 2: Where memory $M^{i, i t r+1}$ in (9) denotes the memory location of $i$ th crow for $i t r+1$ iteration. $M^{i, i t r+1}$ is updated based on the following equation:

$M^{i, i t r+1}=$

$\left\{\begin{array}{l}X^{i, i t r} ; f\left(X^{i, i t r+1}\right) \text { is better than from } f\left(M^{i, i t r}\right) \\ M^{i, i t r} ; \quad \text { othewise }\end{array}\right.$

Crow $j$ knows another crow $i$ is following it. Hence, to restrain its cache from being pilfered, crow $j$ will fly to another position to confuse crow $i$ using the following equation:

$X^{i, i t r+1}=$

$\left\{\begin{array}{l}X^{i, i t r}+r_{i} * f_{l}^{i, i t r} *\left(M^{j, i t r}-X^{i, i t r} ; r_{i} \geq A P_{i}^{i t r}\right) \\ \text { a random position in search space; otherwise }\end{array}\right.$

where $r_{i}$ is a random number between 0 and 1 and $A P_{i}^{i t r}$ denotes the awareness probability of crow $j$ at iteration iter.

\section{Result analysis}

\subsection{Experimental setting}

The simulator will provide production data for specific well placement. Matlab's optimization 
Tab. 2: Economic Parameters used by authors in well placement optimization.

\begin{tabular}{|c|c|c|}
\hline $\begin{array}{c}\text { Economic } \\
\text { parameter }\end{array}$ & Value & Unit \\
\hline CAPEX & $6.4 \mathrm{E} 7$ & $\$$ \\
\hline Oil price & 290.572 & $\$ / \mathrm{STB}$ \\
\hline Gas price & 0.126 & $\$ / \mathrm{MScf}$ \\
\hline $\begin{array}{c}\text { Oil production } \\
\text { cost }\end{array}$ & 72.327 & $\$ / \mathrm{STB}$ \\
\hline $\begin{array}{c}\text { Water production } \\
\text { cost }\end{array}$ & 31.447 & $\$ / \mathrm{STB}$ \\
\hline Discount rate & $10 \%$ & - \\
\hline
\end{tabular}

algorithms will provide the specific location of the well. Figure 3 represents the overall flow diagram for searching the maximum net present value. In each trial, the number of iteration and the number of particles were 100 and 20 respectively for all algorithms. The economic parameters that were used in the (4) to conduct the experiment are listed in Tab. 2 and Tab. 3.

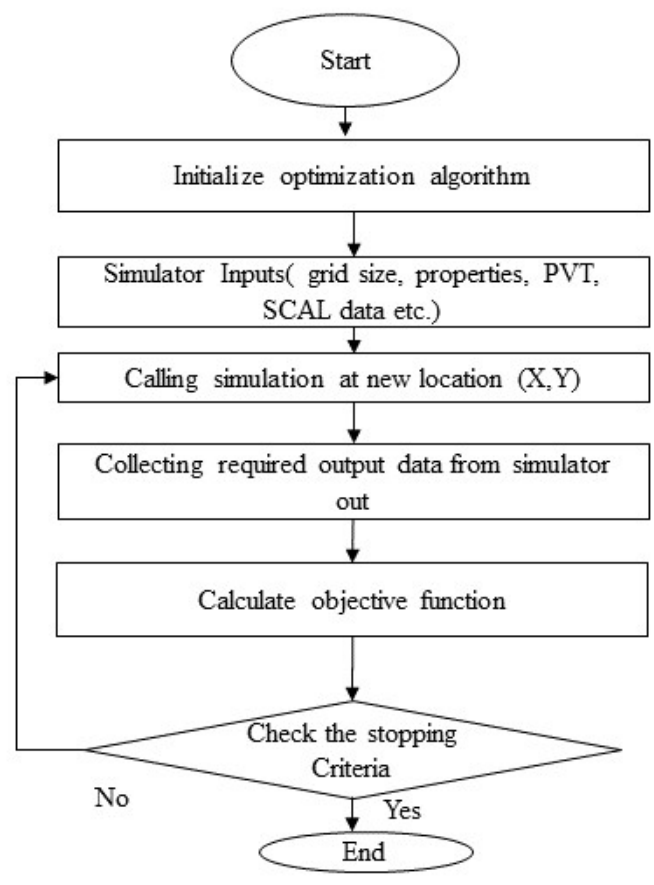

Fig. 3: A general flow chart for searching the maximum net present value.

\subsection{Performance comparison criteria}

To evaluate the performance of the algorithms several criteria was considered for this problem $[36,37]$. So, authors have considered several criteria mentioned below:

Effectiveness is a simple measure of performance and is the average value between tests of the best solution found as a percentage of the global optimum or,

$$
\bar{f}=\frac{1}{N} \sum_{i=1}^{n} N \frac{f\left(\hat{p}_{i}\right)}{f(p *)}
$$

where $f(p)$ is the value of solution $p ; p *$ is the globally optimum solution; $\hat{p}_{i}$ is the best solution found in trial $i$ and $N$ is the number of trials for each algorithm.

Efficiency indicates the speed at which the algorithm reaches a performance level using the number of unique evaluations required to find a solution of at least $98 \%$ the best value of solution found, on average between tests or,

$$
\bar{L}=\frac{1}{N} \sum_{i=1}^{n} N \frac{L_{i}^{98}}{M},
$$

where additionally, $L_{i}^{98}$ is the number of unique function evaluations required to find solution $q$ such that $f(q) \geq 0.98 f\left(\hat{p}_{i}\right)$ for trial $i$ (for minimization) and $M$ is the total number of function evaluations per trial.

Apart from these two criteria, statistical data like standard deviation, average and minmax are data are collected in experimental trials and the results are shown in Tabs. 4 and 6. 5 trials are considered for each algorithm to calculate the mentioned criteria.

Quality of the solution can be obtained from standard deviation. Lower standard deviation means the results of the algorithms are reliable.

Again, Convergence curve is one of the most important factors for evaluating the performance of an algorithm. Convergence curve reveals the convergence speed. 
Tab. 3: Recently applied Metaheuristic algorithms on well placement optimization.

\begin{tabular}{|c|c|c|c|}
\hline Ref. & Years & Technique & Parameter Configuration \\
\hline 1. [13] & 2018 & GA & $\begin{array}{c}\text { Iteration }=100 \\
\text { Swarm size }=20 \\
\text { Crossover }=60 \% \\
\text { Mutation }=5 \%\end{array}$ \\
\hline 2. $[35]$ & 2018 & PSO & $\begin{array}{c}\text { Iteration }=100 \\
\text { Swarm size }=20 \\
\text { Inertial factor }=0.729 \\
c_{1} \& c_{2}=1.494 \\
\text { (Here } c_{1}, c_{2} \\
\text { represents acceleration) }\end{array}$ \\
\hline 3. Proposed & 2012 & FA & $\begin{array}{c}\text { Iteration }=100 \\
\text { Swarm size }=20 \\
\text { The light absorption } \\
\text { coefficient } \gamma=1 \\
\text { brightness of } X_{i} \text { at } r=0, \beta_{0}=2 \\
\text { Mutation Coefficient, alpha, } \alpha=0.2 \\
\text { Mutation Coefficient Damping } \\
\text { Ratio, } \alpha_{0}=0.98\end{array}$ \\
\hline 4. Proposed & 2016 & CSA & $\begin{array}{c}\text { Iteration }=100 \\
\text { Swarm size }=20 \\
\text { Flight length, } f l=2 \\
\text { Awareness Probability, } \mathrm{Ap}=0.3\end{array}$ \\
\hline
\end{tabular}

\subsection{Case study 1}

To conduct the experimental test, the PUNQ-S3 reservoir model is considered. The PUNQ-S3 model is a synthetic reservoir model based on a real field used by Elf Exploration production. It was developed to test methods for quantifying uncertainty assessment. Details of the reservoir model can be found on [38]. The PUNQ-S3 has $19 \times 28 \times 5$ grid blocks. In this study, the authors considered 4 vertical wells to be optimized. Each well has coordinates $(x, y)$. The total number of variables to be optimized in this experiment is therefore $2 \times 4$. The parameters that are used in this case study are listed in Tab. 3. The iteration number and population size for this case study is 100 and 20 repectively.

\section{Statistical and convergence analysis}

Convergence curve is an important tool to analyze the convergence speed of the algorithm and to compare its performance with other algorithms. So, plots of the average NPV of GA,
PSO, CSA and FA algorithms versus the number of iterations are shown in Fig. 4. From Fig. $4 \mathrm{FA}$ is superior to other algorithms for finding better NPV in the PUNQ-S3 reservoir. The second-best algorithm is GA. PSO achieved the third best NPV. GA and PSO both got stuck in local optima. Overall, in case study 1, FA has faster convergence and achieved the highest NPV. However, the CSA algorithm was not able to provide satisfactory NPV.

The results about the max, min, average, standard deviation, effectiveness, and efficiency of NPV for each algorithm are collected from trails and listed in Table. The results in case study 1 show that FF algorithm is best in 5 criteria. However, CSA had superior efficiency. The reason for this phenomenon is that efficiency is calculated with respect to its own best solution. So, despite having lower NPV than other algorithms CSA achieved higher efficiency. The box plot result shown in Fig. 5 depicts that FF has the lowest standard deviation with comparison to other algorithms. 
Tab. 4: Statistical data of applied Metaheuristic algorithms on well placement optimization for PUNQ-S3 reservoir.

\begin{tabular}{|c|c|c|c|c|}
\hline & GA & PSO & CSA & FF \\
\hline Max & $4.07 \mathrm{E}+09$ & $3.93 \mathrm{E}+09$ & $3.26 \mathrm{E}+09$ & $4.00 \mathrm{E}+09$ \\
\hline Min & $3.24 \mathrm{E}+09$ & $3.10 \mathrm{E}+09$ & $2.43 \mathrm{E}+09$ & $3.94 \mathrm{E}+09$ \\
\hline Average & $3.58 \mathrm{E}+09$ & $3.54 \mathrm{E}+09$ & $2.80 \mathrm{E}+09$ & $3.98 \mathrm{E}+09$ \\
\hline $\begin{array}{c}\text { Standard } \\
\text { deviation }\end{array}$ & $3.48 \mathrm{E}+08$ & $3.68 \mathrm{E}+08$ & $3.92 \mathrm{E}+08$ & $3.62 \mathrm{E}+07$ \\
\hline Effectiveness & $8.79 \mathrm{E}-01$ & $8.69 \mathrm{E}-01$ & $6.87 \mathrm{E}-01$ & $9.77 \mathrm{E}-01$ \\
\hline Efficiency & $4.62 \mathrm{E}-01$ & $5.00 \mathrm{E}-01$ & $7.10 \mathrm{E}-01$ & $5.58 \mathrm{E}-01$ \\
\hline
\end{tabular}

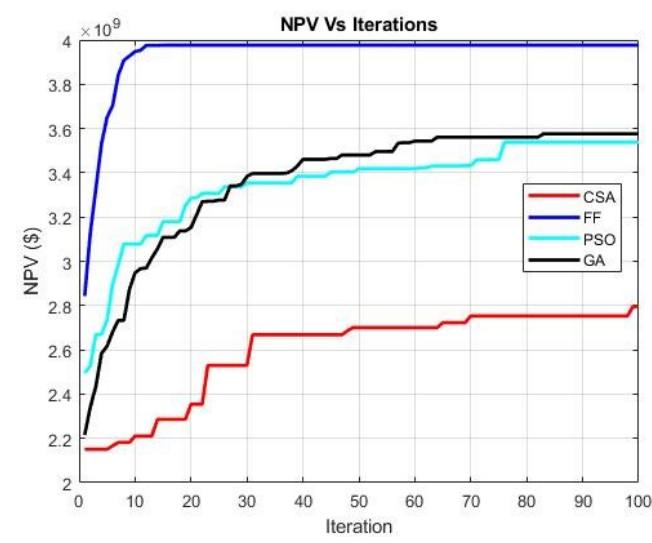

Fig. 4: Convergence curve for PSO, CSA, GA and FA.

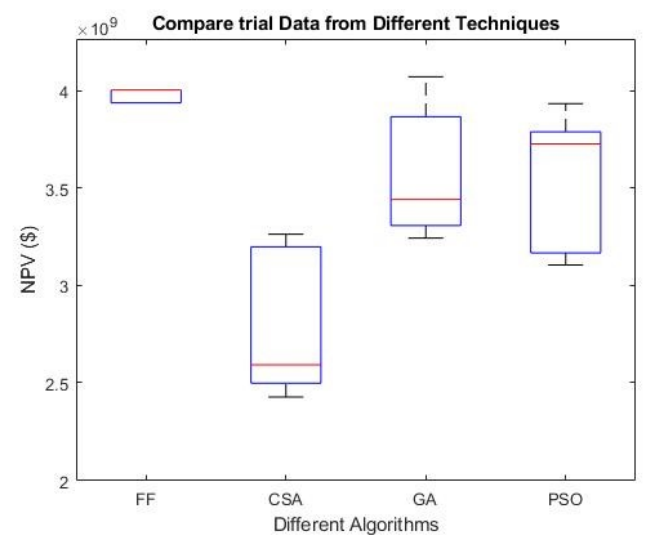

Fig. 5: Boxplot for PSO, CSA, GA and FA.

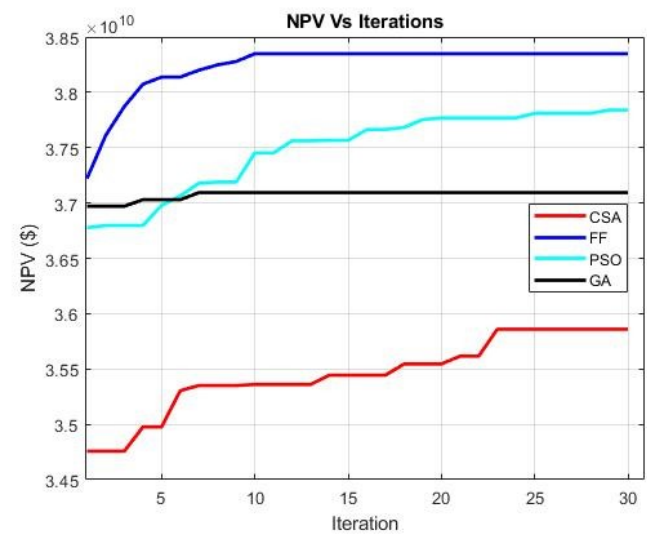

Fig. 6: Convergence curve for PSO, CSA, GA and FA.

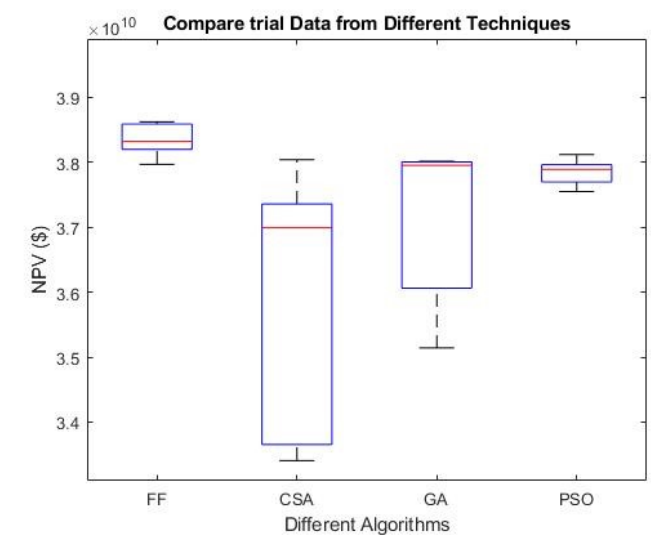

Fig. 7: Box plot for PSO, CSA, GA, and FA. 


\subsection{Case study 2}

To carry out the second case study, the First SPE model is considered. The First SPE model is a synthetic reservoir model based on Three-Dimensional Black Oil Reservoir Simulation Problem. The First SPE model has $10 \times 10 \times 3$ grid blocks. In this study, the authors considered that 2 verticals well to be optimized. Each well has coordinates $(x, y)$. The total number of variables to optimize in this experiment is therefore $2 \times 2$. Table 5 lists the parameter that are used in this experiment. In this case study the number of iteration is 30 and population size is 5 for each algorithm.

\section{Statistical and Convergence Analysis}

From Fig. 6, FA is superior to the other algorithms to find a better NPV in the SPE 1 reservoir model. The second-best algorithm is PSO. However, Crow search algorithm and GA got stuck in local optima. Overall, in case study 2, FA has faster convergence and has found the highest NPV. However, the CSA algorithm again has not been able to provide a satisfactory NPV in case study 2.

Again, the results concerning the max, min, average, standard deviation, effectiveness and efficiency of the NPV for each algorithm are collected from the trials and listed in Tab. 6. The results of the case study of 2 shows that the FF algorithm is better on 5 criteria. However, PSO had less standard deviation. The result of the box plot illustrated in Fig. 7 shows that PSO has the lowest standard deviation compared to other algorithms and FF has the second-lowest standard deviation.

\subsection{Advantage and disadvantage of proposed techniques}

By analyzing the main characteristics of the FA, the following three points for its success can be highlighted:

- FA can perform better than PSO, GA, and CSA to tackle highly nonlinear, multimodal optimization problem as FA can automatically subdivide its population into sub- groups, since local attraction is stronger than long-distance attraction.

- To avoid premature convergence as those in PSO and GA, FA does not update its location based on the personal best information, and there is no explicit global best either.

- FA can work as a DE, SA, and PSO so it has full advantage of these three algorithms [31]. Also, by controlling the scaling parameter FA can adapt to the problem landscape.

No free lunch theorem (NFL) noted that no single algorithm can be best for all problems [39]. In this problem, PSO, GA, CSA, and FA have several benefits and drawbacks. In Tab. 7, the advantage and disadvantages of these algorithms are presented.

This study has limitations, as it is primarily focused on optimization methods. The optimization techniques can be compared with other metaheuristic algorithm in future. Also, History matching, and uncertainty are not considered in this study. Also, proper techniques can be applied

\section{Conclusions}

In this study, the firefly algorithm and crow search algorithm are implemented for well placement optimization and their application with respect to well placement optimization problem is investigated. Experimental results suggested that the firefly algorithm can find a better solution than popular algorithms. However, the crow search algorithm was unable to acquire good results in this problem. Due to strong attraction to local attractor, firefly has a strong local search capacity which helped it to tackle this multimodal problem more efficiently. While a higher net profit value is the focus of this study, several statistical criteria is also considered to evaluate the performance of the algorithms. Firefly algorithm has shown superior performance than PSO, GA, and CSA in those criteria. However, due to its extensive local search it will require more computational time [40]. But, in this problem, as the 
Tab. 5: Recently applied Metaheuristic algorithms on well placement optimization.

\begin{tabular}{|c|c|c|c|}
\hline Ref. & Years & Technique & Parameter Configuration \\
\hline 1. [13] & 2018 & GA & $\begin{array}{c}\text { Iteration }=30 \\
\text { Swarm size }=5 \\
\text { Crossover }=60 \% \\
\text { Mutation }=5 \%\end{array}$ \\
\hline 2. $[35]$ & 2018 & PSO & $\begin{array}{c}\text { Iteration }=30 \\
\text { Swarm size }=5 \\
\text { Inertial factor }=0.729 \\
c_{1} \& c_{2}=1.494 \\
\text { (Here } c_{1}, c_{2} \\
\text { represents acceleration) }\end{array}$ \\
\hline 3. Proposed & 2012 & FA & $\begin{array}{c}\text { Iteration }=30 \\
\text { Swarm size }=5 \\
\text { The light absorption } \\
\text { coefficient } \gamma=1 \\
\text { brightness of } X_{i} \text { at } r=0, \beta_{0}=2 \\
\text { Mutation Coefficient, alpha, } \alpha=0.2 \\
\text { Mutation Coefficient Damping } \\
\text { Ratio, } \alpha_{0}=0.98\end{array}$ \\
\hline 4. Proposed & 2016 & CSA & $\begin{array}{c}\text { Iteration }=30 \\
\text { Swarm size }=5 \\
\text { Flight length, } f l=2 \\
\text { Awareness Probability, } \mathrm{Ap}=0.3\end{array}$ \\
\hline
\end{tabular}

Tab. 6: Statistical data of applied Metaheuristic algorithms on well placement optimization for case study 2 .

\begin{tabular}{|c|c|c|c|c|}
\hline & CSA & PSO & FF & GA \\
\hline Max & $3.80 \mathrm{E}+10$ & $3.81 \mathrm{E}+10$ & $3.86 \mathrm{E}+10$ & $3.80 \mathrm{E}+10$ \\
\hline Min & $3.34 \mathrm{E}+10$ & $3.75 \mathrm{E}+10$ & $3.80 \mathrm{E}+10$ & $3.51 \mathrm{E}+10$ \\
\hline Average & $3.59 \mathrm{E}+10$ & $3.78 \mathrm{E}+10$ & $3.83 \mathrm{E}+10$ & $3.71 \mathrm{E}+10$ \\
\hline $\begin{array}{c}\text { Standard } \\
\text { deviation }\end{array}$ & $2.13 \mathrm{E}+09$ & $2.11 \mathrm{E}+08$ & $2.64 \mathrm{E}+08$ & $1.30 \mathrm{E}+09$ \\
\hline Effectiveness & $9.31 \mathrm{E}-01$ & $9.80 \mathrm{E}-01$ & $9.93 \mathrm{E}-01$ & $9.61 \mathrm{E}-01$ \\
\hline Efficiency & $1.73 \mathrm{E}-01$ & $1.30 \mathrm{E}-01$ & $2.46 \mathrm{E}-01$ & $1.00 \mathrm{E}-01$ \\
\hline
\end{tabular}


Tab. 7: Advantages and disadvantages of discussed techniques.

\begin{tabular}{|c|c|c|}
\hline Techniques & Advantages & Disadvantages \\
\hline GA & $\begin{array}{l}\text { + Easy to incorporate discrete } \\
\text { decision variables. } \\
+ \text { Initializing itself from } \\
\text { possible solutions. } \\
+ \text { Higher NPV is achieved } \\
\text { than GA }\end{array}$ & $\begin{array}{l}+ \text { Tuning the algorithm is hard. } \\
+ \text { The convergence and stability } \\
\text { linked with the crossover } \\
\text { and mutation rates. } \\
+ \text { Less efficient than PSO. }\end{array}$ \\
\hline PSO & $\begin{array}{l}\text { + Less parameter to tune. } \\
+ \text { Simple structure and less } \\
\text { dependent on initial points. } \\
+ \text { Incorporating discrete } \\
\text { variable is easy. }\end{array}$ & $\begin{array}{l}\text { + Trapped in local optima due to } \\
\text { weak local search. } \\
+ \text { A high standard deviation and } \\
\text { low efficiency are observed. }\end{array}$ \\
\hline FA & $\begin{array}{l}+ \text { Low Standard deviation } \\
\text { is observed } \\
+ \text { Better local search } \\
+ \text { With respect to standard } \\
\text { deviation, } \\
\text { efficiency and effectiveness } \\
\text { Firefly algorithm is better } \\
\text { than other three algorithms. }\end{array}$ & $\begin{array}{l}+ \text { Computationally expensive } \\
+ \text { Extensive local search } \\
\text { causes higher number of } \\
\text { function evaluation }\end{array}$ \\
\hline CSA & $\begin{array}{l}+ \text { Less parameter to tune. } \\
+ \text { Faster convergence. } \\
+ \text { Easy Implementation. }\end{array}$ & $\begin{array}{l}\text { Less effective in nonlinear } \\
\text { Optimization. } \\
+ \text { Trapped in local Optima. }\end{array}$ \\
\hline
\end{tabular}

net profit value is counted in billions, higher net profit value is much more important than computational time. Future optimization studies should focus on combining the location of the well, well control parameters, and matching history. By harnessing equation less Convolutional Neural Network (CNN), we can retain the flexibility to quantify the uncertainty of different well-controls. For better approaches, researchers have recently merged quantum computing with current metaheuristic optimization algorithms. Quantum-based optimization techniques were applied in several complex engineering applications using quantum parallelism mechanism. Additionally, we suggest using the global search algorithm with a local search approach, because it may have the advantage of solving well placement optimization problem successfully. Lots of research papers have used proxy models in recent years to replace actual reservoir simulators, and these models have been found to minimize runtime. The accuracy of this alternative model therefore depends on its range of sampling. Fu- ture research in this area may focus on improving the reliability of this technique.

\section{Acknowledgments}

The authors would like to sincerely thank and highly appreciate Petroleum Research Fund (PRF), Cost Center 0153AB-A33 and the project leader Assoc. Prof. Dr. Eswaran Padmanabhan for supporting the research. The authors also would like to thank the Center of Graduate Studies of the University of Technology PETRONAS and Fundamental and Applied Science Department of University of Technology PETRONAS for their invaluable support. 


\section{Nomenclature}

$\begin{array}{ll}\text { ABC } & \text { Artificial Bee colony } \\ \mathrm{C}_{w} & \text { Cost per unit volume of } \\ & \text { produced water (\$/STB) } \\ \text { CSA } & \text { Crow Search Algorithm } \\ \text { CAPEX } & \text { Capital expenditure (\$) } \\ \text { D } & \text { Discount rate (fraction) } \\ \text { GA } & \text { Genetic Algorithm } \\ \text { ICA } & \text { Imperialist Competitive } \\ & \text { Algorithm } \\ \text { MA } & \text { Metaheuristic algorithms } \\ \text { NPV } & \text { Net present value }(\$) \\ \text { NFL } & \text { No Free Lunch theorem } \\ \text { O-CSMADS } & \text { Meta-optimized hybrid cat } \\ & \text { swarm MADS } \\ \text { OPEX } & \text { Operational expenditure (\$) } \\ \text { PUNQ-S3 } & \text { A synthetic Reservoir } \\ \text { PSO } & \text { Particle Swarm Optimization } \\ \text { P } & \text { Oil price (\$STB) } \\ \text { QPSO } & \text { Quantum Particle Swarm } \\ & \text { optimization } \\ \text { Q } w & \text { Cumulative water production } \\ \text { Q } & \text { (STB) } \\ \text { PSO } & \text { Cumulative oil production } \\ \text { SPE-1 } & \text { (STB) } \\ \text { T } & \text { Particle Swarm Optimization } \\ \text { WPO } & \text { A Synthetic Reservoir } \\ & \text { Number of years } \\ & \text { Well placement optimization }\end{array}$

\section{References}

[1] Al Dossary, M. A., \& Nasrabadi, H. (2016). Well placement optimization using imperialist competitive algorithm. Journal of Petroleum Science and Engineering, 147, 237-248.

[2] Siavashi, M., Tehrani, M. R., \& Nakhaee, A. (2016). Efficient particle swarm optimization of well placement to enhance oil recovery using a novel streamline-based objective function. Journal of Energy Resources Technology, 138(5), 1-9.

[3] Yu, W., \& Sepehrnoori, K. (2014). An efficient reservoir-simulation approach to design and optimize unconventional gas production. Journal of Canadian Petroleum Technology, 53(02), 109-121.
[4] Humphries, T. D., Haynes, R. D., \& James, L. A. (2014). Simultaneous and sequential approaches to joint optimization of well placement and control. Computational Geosciences, 18(3-4), 433-448.

[5] Ariadji, T., Haryadi, F., Rau, I. T., Aziz, P. A., \& Dasilfa, R. (2014). A novel tool for designing well placements by combination of modified genetic algorithm and artificial neural network. Journal of Petroleum Science and Engineering, 122, 69-82.

[6] Islam, J., Vasant, P. M., Negash, B. M., Laruccia, M. B., Myint, M., \& Watada, J. (2020). A holistic review on artificial intelligence techniques for well placement optimization problem. Advances in Engineering Software, 141, 102767.

[7] Onwunalu, J. E., \& Durlofsky, L. J. (2010). Application of a particle swarm optimization algorithm for determining optimum well location and type. Computational Geosciences, 14(1), 183.

[8] Zandvliet, M., Handels, M., van Essen, G., Brouwer, R., \& Jansen, J. D. (2008). Adjoint-based well-placement optimization under production constraints. Spe Journal, 13(04), 392-399.

[9] Rosenwald, G. W., \& Green, D. W. (1974). A method for determining the optimum location of wells in a reservoir using mixedinteger programming. Society of Petroleum Engineers Journal, 14(01), 44-54.

[10] Ma, X., Plaksina, T., \& Gildin, E. (2013). Integrated horizontal well placement and hydraulic fracture stages design optimization in unconventional gas reservoirs. In SPE Unconventional Resources Conference Canada. Society of Petroleum Engineers, 112.

[11] Guyaguler, B., \& Horne, R. N. (2001, January). Uncertainty assessment of well placement optimization. In SPE annual technical conference and exhibition. Society of Petroleum Engineers, 1-13.

[12] Emerick, A. A., Silva, E., Messer, B., Almeida, L. F., Szwarcman, D., Pacheco, 
M. A. C., \& Vellasco, M. M. B. R. (2009, January). Well placement optimization using a genetic algorithm with nonlinear constraints. In SPE reservoir simulation symposium. Society of Petroleum Engineers, 120.

[13] Lyons, J., \& Nasrabadi, H. (2013). Well placement optimization under timedependent uncertainty using an ensemble Kalman filter and a genetic algorithm. Journal of Petroleum Science and Engineering, 109, 70-79.

[14] Chang, Y., Bouzarkouna, Z., \& Devegowda, D. (2015). Multi-objective optimization for rapid and robust optimal oilfield development under geological uncertainty. Computational Geosciences, 19(4), 933-950.

[15] Ariadji, T., Sukarno, P., Sidarto, K. A., Soewono, E., Riza, L. S., \& David, K. (2012). Optimization of vertical well placement for oil field development based on basic reservoir rock properties using a genetic algorithm. Journal of Engineering and Technological Sciences, 44(2), 106-127.

[16] Montes, G., Bartolome, P., \& Udias, A. L. (2001). The use of genetic algorithms in well placement optimization. In SPE Latin American and Caribbean petroleum engineering conference. Society of Petroleum Engineers, 1-10.

[17] Goldberg, D. E. (1989). Genetic algorithms in search. Optimization, and MachineLearning, Addison Wesley, Reading: MA, 372 pages.

[18] Jefferys, E. R. (1993, January). Design applications of genetic algorithms. In SPE Annual Technical Conference and Exhibition. Society of Petroleum Engineers, 1-4.

[19] Onwunalu, J. (2010). Optimization of field development using particle swarm optimization and new well pattern descriptions (Doctoral dissertation, Stanford University).

[20] Feng, Q., Zhang, J., Zhang, X., \& Hu, A. (2012). Optimizing well placement in a coalbed methane reservoir using the particle swarm optimization algorithm. International Journal of Coal Geology, 104, 34-45.

[21] Clerc, M. (1999). The swarm and the queen: towards a deterministic and adaptive particle swarm optimization. In Proceedings of the 1999 congress on evolutionary computation-CEC99 (Cat. No. 99TH8406), 3, 1951-1957. IEEE.

[22] Foroud, T., Baradaran, A., \& Seifi, A. (2018). A comparative evaluation of global search algorithms in black box optimization of oil production: A case study on Brugge field. Journal of Petroleum Science and Engineering, 167, 131-151.

[23] D'andreagiovanni, F., Krolikowski, J., \& Pulaj, J. (2015). A fast hybrid primal heuristic for multiband robust capacitated network design with multiple time periods. Applied Soft Computing, 26, 497-507.

[24] Gambardella, L. M., Montemanni, R., \& Weyland, D. (2012). Coupling ant colony systems with strong local searches. European Journal of Operational Research, 220(3), 831-843.

[25] Whitley, D., Gordon, V. S., \& Mathias, K. (1994). Lamarckian evolution, the Baldwin effect and function optimization. In International Conference on Parallel Problem Solving from Nature, Springer, Berlin, Heidelberg, 5-15.

[26] Woźniak, M., \& Połap, D. (2015). On some aspects of genetic and evolutionary methods for optimization purposes. International Journal of Electronics and Telecommunications, 61(1), 7-16.

[27] Nwankwor, E., Nagar, A. K., \& Reid, D. C. (2013). Hybrid differential evolution and particle swarm optimization for optimal well placement. Computational Geosciences, 17(2), 249-268.

[28] Al Dossary, M. A., \& Nasrabadi, H. (2016). Well placement optimization using imperialist competitive algorithm. Journal of Petroleum Science and Engineering, 147, 237-248. 
[29] Siddiqui, M. A. Q., Khan, R. A., \& Jamal, M. S. (2015). Multi-objective well placement optimization considering energy sustainability along with economical gains. In SPE North Africa Technical Conference and Exhibition. Society of Petroleum Engineers, $1-8$.

[30] Yang, X. S. (2009, October). Firefly algorithms for multimodal optimization. In International symposium on stochastic algorithms, Springer, Berlin, Heidelberg, 169178

[31] Fister, I., Fister Jr, I., Yang, X. S., \& Brest, J. (2013). A comprehensive review of firefly algorithms. Swarm and Evolutionary Computation, 13, 34-46.

[32] Pal, S. K., Rai, C. S., \& Singh, A. P. (2012). Comparative study of firefly algorithm and particle swarm optimization for noisy nonlinear optimization problems. International Journal of intelligent systems and applications, $4(10), 50$.

[33] Kennedy, J., \& Eberhart, R. (1995). Particle swarm optimization. In Proceedings of ICNN'95-International Conference on Neural Networks, 4, 1942-1948. IEEE.

[34] Askarzadeh, A. (2016). A novel metaheuristic method for solving constrained engineering optimization problems: crow search algorithm. Computers \& Structures, 169, 112.

[35] Khan, R. A., \& Awotunde, A. A. (2018). Determination of vertical/horizontal well type from generalized field development optimization. Journal of Petroleum Science and Engineering, 162, 652-665.

[36] Clerc, M. (2011). From theory to practice in particle swarm optimization. In Handbook of Swarm Intelligence, Springer, Berlin, Heidelberg, 3-36.

[37] Bangerth, W., Klie, H., Wheeler, M. F., Stoffa, P. L., \& Sen, M. K. (2006). On optimization algorithms for the reservoir oil well placement problem. Computational Geosciences, 10(3), 303-319.
[38] Floris, F. J., Bush, M. D., Cuypers, M., Roggero, F., \& Syversveen, A. R. (2001). Methods for quantifying the uncertainty of production forecasts: a comparative study. Petroleum Geoscience, 7(S), S87-S96.

[39] Wolpert, D. H., \& Macready, W. G. (1997). No free lunch theorems for optimization. IEEE transactions on evolutionary computation, 1(1), 67-82.

[40] Yeten, B., Durlofsky, L. J., \& Aziz, K. (2003). Optimization of nonconventional well type, location, and trajectory. SPE Journal, 8(03), 200-210.

\section{About Authors}

Junzo WATADA received his B.Sc. and M.Sc. degrees in electrical engineering from Osaka City University, Japan, and his Ph.D degree from Osaka Prefecture University, Japan. Currently, he is a Professor Emeritus at Waseda University. $\mathrm{He}$ is the president of Forum for Interdisciplinary Mathematics (2019-2021). He is a Life Fellow of the Japan Society for Fuzzy Theory and intelligent informatics (SOFT). Prof Watada is an IEEE senior member, Executive Chair of ISME, WCICME. He is a Co-principal Editor, a Co-Editor and an Associate Editor of various international journals, including IDT journal, ICIC Express Letters, International Journal of Systems and Control Engineering, and Fuzzy Optimization \& Decision Making. His professional interests include human centric data mining, soft computing, tracking systems, knowledge engineering, financial engineering and management engineering.

Pandian VASANT ( $\mathrm{H}$ index: 30 ) is a senior lecturer at University of Technology Petronas and an Editor-in-Chief of IJEOE (ESCI/WoS). He holds PhD in Computational Intelligence (UNEM, Costa Rica), MSc (UMS, Malaysia, Engineering Mathematics) and BSc (Hons) in Mathematics (MU, Malaysia). His research interests include Soft Computing, Hybrid Optimization, Innovative Computing and Applications. 
He has co-authored research articles in journals, conference proceedings, presentation, special issues guest editor, book chapters (257 publications indexed in Web of Science). In the year 2009 and 2015, Dr. Pandian Vasant was awarded top reviewer and outstanding reviewer for the journal Applied Soft Computing (Elsevier).
He has 26 years of working experiences at the universities. Currently he is Editor-in-Chief of International Journal of Energy Optimization \& Engineering, and Member of AMS (USA), NAVY Research Group (TUO, Czech Republic) and MERLIN Research Group (TDTU, Vietnam). 